\title{
Effects of exogenous addition of cadmium on cadmium speciation in hyperaccumulator of Sedum alfredii Hance
}

\author{
Jiawei Yang ${ }^{1}$, Lin Sun ${ }^{1,2}$, Xing Shen ${ }^{1}$, Changsheng Peng ${ }^{1,2^{*}}$ \\ ${ }^{1}$ The Key Lab of Marine Environmental Science and Ecology, Ministry of Education, College of Environmental Science and Engineering, \\ Ocean University of China, Qingdao 266100, China; \\ ${ }^{2}$ School of Environmental and Chemical Engineering, Zhaoqing University, Zhaoqing, 526061, China.
}

\begin{abstract}
Abtract. Continuous chemical extraction is considered to be one of the most common methods for the extraction of heavy metals speciations in plants. However, the basis for the extraction order of this method is not explained and has been rarely studied. In this paper, we analyzed the speciations of cadmium in plants by a four-step continuous extraction method. The extraction sequence of ethanol and water was studied to study the effect of extraction sequence on the extraction rate of extraction agent. The results showed that cadmium exists mostly in $\mathrm{NaCl}$ extraction state and the extraction rate of the two kinds of extraction agents decreased when the order of ethanol and water was changed.
\end{abstract}

\section{Introduction}

Sedum alfredii Hance, an ancient lead-zinc mine in Yazhou city, Zhejiang province, is known to be a cadmium hyperaccumulator that can transport heavy metals (HMs) to the ground through its roots. The absorption of HMs by plants and their migration and transformation in plants are hot topics. Chemical continuous extraction is considered to be a common method to study the speciation of HMs in plants. The extracting agents for different forms of HMs are mostly $\mathrm{NaCl}$, ethanol, hydrochloric acid, deionized water, acetic acid, organic solvent, etc ${ }^{[1-3]}$. And different extracting agents have different extraction rate for HMs. However, in many literatures, the reasons for the selection of extractant have not been explained. In this paper, four extractants, $80 \%$ ethanol, deionized water, $\mathrm{NaCl}$ and $2 \%$ acetic acid, were used to extract speciations of $\mathrm{Cd}$ in Sedum alfredii Hance. In order to explore the effect of the order of extraction agents on the extraction rate, the extraction order of ethanol and water was changed in this paper.

\section{Material and methods}

\subsection{Plant cultivation}

The experimental material was hyperaccumulator Sedum alfredii Hance, purchased from Hangzhou Lusheng Institute of Modern Agriculture and Environmental Ecology. The purchased branches were washed with tap water, the roots were removed, and the branches were cut into uniform branches with a height of $3-4 \mathrm{~cm}$. The branches were germinated in clear water for 15 days in an incubator, and then cultured in 1/8 Holland nutrient

${ }^{*}$ Corresponding author: Email: cspeng@sohu.com;

pcs005@ouc.edu.cn; Tel.: +86 15653229653 solution for 6 days and 1/4 Holland nutrient solution for 14 days. The nutrient composition is: $0.1 \mathrm{mM} \mathrm{KH}_{2} \mathrm{PO}_{4}$, $0.5 \mathrm{mM} \mathrm{MgSO}_{4} \cdot 7 \mathrm{H}_{2} \mathrm{O}, 0.1 \mathrm{mM} \mathrm{KCl}, 0.7 \mathrm{mM} \mathrm{K}_{2} \mathrm{SO}_{4}, 2$ $\mathrm{mM} \quad \mathrm{Ca}\left(\mathrm{NO}_{3}\right)_{2} \cdot 4 \mathrm{H}_{2} \mathrm{O}, \quad 10 \quad \mu \mathrm{M} \quad \mathrm{H}_{3} \mathrm{BO}_{3}, \quad 0.01 \quad \mu \mathrm{M}$ $\left(\mathrm{NH}_{4}\right)_{6} \mathrm{Mo}_{7} \mathrm{O}_{24} \cdot 4 \mathrm{H}_{2} \mathrm{O}, 0.2 \mu \mathrm{M} \quad \mathrm{CuSO}_{4} \cdot 5 \mathrm{H}_{2} \mathrm{O}, 1 \mu \mathrm{mM}$ $\mathrm{ZnSO}_{4} \cdot 7 \mathrm{H}_{2} \mathrm{O}, 0.5 \mu \mathrm{M} \mathrm{MnSO}_{4} \cdot \mathrm{H}_{2} \mathrm{O}, 100 \mu \mathrm{M}$ FeEDTA. The environment of the incubator was $26 / 20^{\circ} \mathrm{C}$, photosynthetically active radiation was $500 \mathrm{umolm}^{-2} \mathrm{~s}^{-1}$, illumination intensity was $2500 \mathrm{Lux}, 70-80 \%$ relative humidity, water was changed every three days and ventilation was maintained all day long.

\subsection{Cadmium exposure and sample pretreatment}

Sedum alfredii Hance was cultured in nutrient solution containing $20 \mathrm{mg} / \mathrm{L}$ and $100 \mathrm{mg} / \mathrm{L} \mathrm{Cd}^{2+}$ for 9 days, and three parallel samples were set for each treatment. After harvest, the whole plant was divided into three parts: roots, stems and leaves. The roots were soaked in $20 \mathrm{mM}$ $\mathrm{Na}_{2}$-EDTA for 15 minutes to remove the $\mathrm{Cd}^{2+}$ on the roots surface ${ }^{[4]}$. Then clean it with deionized water for several times, dry it with absorbent paper, freeze dry it in a freeze-dryer (FD-1A-80) and store it at room temperature for later use. Leaves and stems were washed several times with deionized water, dried with absorbent paper, then freeze-dried in a freeze-dryer and stored at room temperature for later use.

\subsection{Extraction of different speciation of cadmium}

The freeze-dried samples were ground evenly with a mortar and pestle and extracted by two methods. The first method, which is called the four-step continuous extraction method, refers to the four-step extraction method of Wang et al. The extraction agent and 
extraction speciation are respectively. $80 \%$ ethanol: extraction of inorganic salts and amino acid salts based on nitrate and chloride; deionized water: extraction of water-soluble organic acid salts, HMs generation of phosphate, etc.; $1 \mathrm{~mol} / \mathrm{L} \mathrm{NaCl}$ : extraction of pectate, $\mathrm{HMs}$ bound to protein or adsorbed state, etc.; $2 \%$ acetic acid: extraction of water insoluble HMs phosphate, including second generation phosphate, orthophosphate, etc.

The second method uses a two-step extraction method, the first step is extracted with deionized water, and the second step is extracted with $80 \%$ ethanol (i.e. switching the order of the first two steps in the four-step extraction method). The specific operation steps are as follows: take about $0.2 \mathrm{~g}$ of the sample and immerse it in $25 \mathrm{ml}$ of the extractant overnight, then extract the precipitate with $25 \mathrm{ml}$ of the extractant for 3 times with a time interval of 2 hours, extract it for 4 times in total, and collect $100 \mathrm{ml}$ of the supernatant. The supernatant of each extraction is filtered by a filter membrane, and the solids on the filter membrane are flushed to the solid precipitate with extractant. Each extraction step follows the above process.

\subsection{Determination of the content of each speciation}

$100 \mathrm{~mL}$ of supernatant extracted from ethanol, water and hydrochloric acid was placed on an electric heating plate at $70^{\circ} \mathrm{C}$ and evaporated to about $2 \mathrm{ml} .10 \mathrm{~mL}$ of supernatant extracted from $\mathrm{NaCl}$ and acetic acid was evaporated to about $2 \mathrm{ml}$ and then digested with a microwave digestion apparatus $\left(\mathrm{HNO}_{3}: \mathrm{H}_{2} \mathrm{O}_{2}, 5: 1\right)$. After digestion, ethanol and water were extracted to $25 \mathrm{ml}$, and $\mathrm{NaCl}$ and acetic acid were extracted to $10 \mathrm{~mL}$. The residue was steamed and dried with an electric hot plate and digested under the same conditions, then the volume was constant to $10 \mathrm{~mL}$. The digestion solution was filtered with $0.45 \mu \mathrm{m}$ membrane and stored at $4^{\circ} \mathrm{C}$ for later use. Finally, the cadmium content was analyzed by atomic absorption spectroscopy (AA7000).

\subsection{Data processing}

All data were correlated and statistically analyzed using Excel 2019 and SPSS packets (version\#24.0). Data were analyzed by univariate ANOVA, and when the P-value detected by ANOVA F was less than 0.05 , the difference between the means was considered significant. Finally, use Orig8.0 drawing software to draw the graph.

\section{Results}

\subsection{Analysis of total speciation and recovery rate}

Four extraction agents $(80 \%$ ethanol, deionized water, $\mathrm{NaCl}$, acetic acid) were used for continuous extraction of the three parts of Sedum alfredii Hance roots, stems and leaves, respectively. The extraction results are shown in Table 1. Under the treatment of $20 \mathrm{mg} / \mathrm{L} \mathrm{Cd}$, the contents of ethanol, water, $\mathrm{NaCl}$, acetic acid and residue in roots were $75.96 \mathrm{ug}, 2.52 \mathrm{ug}, 0.85 \mathrm{ug}, 0.54 \mathrm{ug}$ and $0.01 \mathrm{ug}$, respectively. The content of each extracted state in the stem was 12.86ug for ethanol, 80.58ug for water, 32.90ug for $\mathrm{NaCl}, 8.50 \mathrm{ug}$ for acetic acid and $0.02 \mathrm{ug}$ for residue. The extracted contents of leaves were 104.61ug, 99.41ug, $173.11 \mathrm{ug}, 14.56 \mathrm{ug}$ and $0.07 \mathrm{ug}$, respectively. It can be seen from the data that the content of $\mathrm{Cd}$ in the residue state can be almost ignored by the extraction of the four extractant

Table 1 The content of different speciation in root, stem and leaf of Sedum alfredii Hance

\begin{tabular}{|c|c|c|c|c|c|c|c|c|}
\hline \multirow{2}{*}{$\begin{array}{c}\text { Cd treatment } \\
(\mathrm{mg} / \mathrm{L})\end{array}$} & \multirow{2}{*}{$\begin{array}{c}\text { Plant } \\
\text { organs }\end{array}$} & \multicolumn{5}{|c|}{ The content of different speciation (ug) } & \multirow[b]{2}{*}{ Recycled (ug) } & \multirow{2}{*}{$\begin{array}{l}\text { Actual content } \\
\text { (ug) }\end{array}$} \\
\hline & & $80 \%$ ethanol & $\begin{array}{c}\text { Deionized } \\
\text { water }\end{array}$ & $\mathrm{NaCl}$ & Acetic acid & Residue & & \\
\hline \multirow{3}{*}{20} & root & $75.96 \pm 3.80$ & $2.52 \pm 0.11$ & $0.85 \pm 0.03$ & $0.54 \pm 0.01$ & $0.01 \pm 0.00$ & $79.88 \pm 3.99$ & $69.84 \pm 2.11$ \\
\hline & stem & $12.86 \pm 0.26$ & $80.58 \pm 3.22$ & $32.90 \pm 0.66$ & $8.50 \pm 0.25$ & $0.02 \pm 0.00$ & $134.85 \pm 5.39$ & $156.58 \pm 6.26$ \\
\hline & leaf & $104.61 \pm 6.21$ & $99.41 \pm 3.98$ & $173.11 \pm 6.92$ & $14.56 \pm 0.58$ & $0.07 \pm 0.00$ & $391.77 \pm 22.51$ & $374.29 \pm 15.11$ \\
\hline \multirow{3}{*}{100} & root & $15.23 \pm 0.61$ & $1.90 \pm 0.08$ & $33.95 \pm 1.35$ & $0.75 \pm 0.03$ & $0.03 \pm 0.00$ & $51.85 \pm 1.56$ & $42.25 \pm 1.27$ \\
\hline & stem & $16.93 \pm 0.51$ & $29.92 \pm 0.59$ & $116.26 \pm 3.49$ & $10.87 \pm 0.11$ & $0.16 \pm 0.01$ & $174.15 \pm 5.22$ & $137.10 \pm 5.48$ \\
\hline & leaf & $26.56 \pm 1.06$ & $29.33 \pm 1.74$ & $154.65 \pm 6.19$ & $16.01 \pm 0.31$ & $0.24 \pm 0.01$ & $226.77 \pm 9.07$ & $235.02 \pm 12.45$ \\
\hline
\end{tabular}

The percentage of the total amount of Cd extracted by four extractants and the actual amount of $\mathrm{Cd}$ in the plant was the recovery rate of $\mathrm{Cd}$. The recoveries of roots, stems and leaves were $114.37 \%, 86.12 \%$ and $104.67 \%$ under $20 \mathrm{mg} / \mathrm{L} \mathrm{Cd}$ treatment. The recoveries of roots, stems and leaves were $122.72 \%, 127.02 \%$ and $96.49 \%$ under $100 \mathrm{mg} / \mathrm{L} \mathrm{Cd}$ treatment, respectively. The recovery range was between $86.12 \%$ and $127.02 \%$, which was similar to the recovery range of HMs extracted by $\mathrm{Li}$ through continuous extraction method ${ }^{[5]}$ and met the requirements of speciation analysi

Table 2 The recovery rates of different speciation in root, stem and leaf of Sedum alfredii Hance

\begin{tabular}{|c|c|c|c|c|c|c|c|}
\hline \multirow[b]{2}{*}{$\begin{array}{c}\text { Cd } \\
\text { Treatment }(\mathrm{mg} / \mathrm{L})\end{array}$} & \multirow[b]{2}{*}{ Plant organs } & \multicolumn{6}{|c|}{ Recovery rate $(\%)$} \\
\hline & & $80 \%$ ethanol & $\begin{array}{c}\text { Deionized } \\
\text { water }\end{array}$ & $\mathrm{NaCl}$ & Acetic acid & Residue & Recovery rate \\
\hline 20 & $\begin{array}{l}\text { root } \\
\text { stem }\end{array}$ & $\begin{array}{c}95.09 \pm 4.35 \\
9.53 \pm 0.25\end{array}$ & $\begin{array}{c}3.16 \pm 0.11 \\
59.75 \pm 2.57\end{array}$ & $\begin{array}{c}1.07 \pm 0.02 \\
24.40 \pm 1.05\end{array}$ & $\begin{array}{l}0.67 \pm 0.01 \\
6.31 \pm 0.22\end{array}$ & $\begin{array}{l}0.01 \pm 0.00 \\
0.01 \pm 0.00\end{array}$ & $\begin{array}{c}114.37 \pm 4.57 \\
86.12 \pm 3.44\end{array}$ \\
\hline
\end{tabular}




\section{0

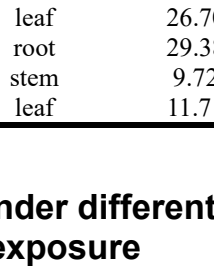

As shown in Fig.1, the acetic acid extraction state of Sedum alfredii Hance under the exposue of $20 \mathrm{mg} / \mathrm{L} \mathrm{Cd}$ showed significant differences with the ethanol extraction state, water extraction state and $\mathrm{NaCl}$ extraction state $(\mathrm{p}<0.05)$. Ethanol, water and $\mathrm{NaCl}$ accounted for $31.89 \%$, $30.09 \%$ and $34.11 \%$ of the total, respectively, and acetic acid accounted for $23.6 \%$. Under the exposure of $100 \mathrm{mg} / \mathrm{L} \mathrm{Cd}$, the proportion of $\mathrm{NaCl}$ extraction was the highest, $67.33 \%$, which showed significant difference with other extraction states $(p<0.05)$. There was no significant difference in ethanol, water and acetic acid extracts, which accounted for $12.97 \%, 13.5 \%$ and $6.1 \%$ of the total, respectively. It can also be seen from the figure that the extraction rate of $\mathrm{NaCl}$ was the highest at the two concentrations, followed by ethanol and water extraction, and the extraction rate was basically the same.

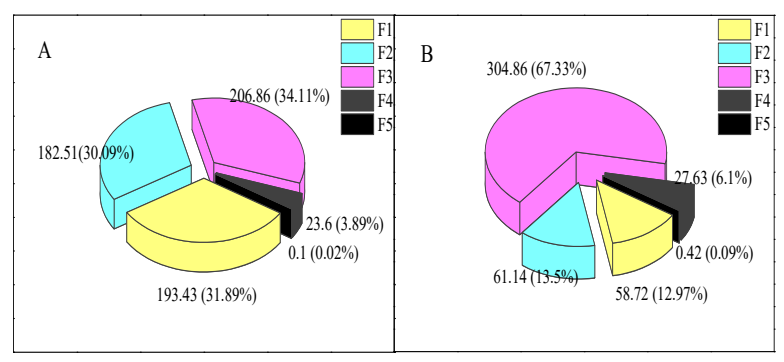

Fig.1 Speciation in Sedum alfredii Hance under 20mg/L (A) and $100 \mathrm{mg} / \mathrm{L}(\mathrm{B}) \mathrm{Cd}$ exposure

Fraction 1: $80 \%$ ethanol extraction speciation; Fraction 2: Deionized water extraction speciation; Fraction 3: $0.1 \mathrm{~mol} / \mathrm{L}$ $\mathrm{NaCl}$ extraction speciation; Fraction 4: 2\% acetic acid extraction speciation; Fraction 5: residual speciation

\subsection{Speciation of $\mathrm{Cd}$ in root, stem and leaf}

There were obvious differences in the speciation of $\mathrm{Cd}$ in the roots, stems and leaves. Different concentrations of $\mathrm{Cd}$ also have an effect on the transformation of $\mathrm{Cd}$ speciation. This section mainly analyzes the speciation of $\mathrm{Cd}$ in roots, stems and leaves and the effects of different concentrations of $\mathrm{Cd}$ on speciation.

As shown in Fig.2, Cd speciation in roots were significantly different under exposure of different concentrations of $\mathrm{Cd}$. Under the exposure of $20 \mathrm{mg} / \mathrm{L} \mathrm{Cd}$, $\mathrm{Cd}$ mainly existed in ethanol form $(95.09 \%), 3.61 \%$ in water form, and only $1.74 \%$ in $\mathrm{NaCl}$ and acetic acid form. The forms of $\mathrm{Cd}$ in roots mainly existed in ethanol and water extraction states. Under the exposure of $100 \mathrm{mg} / \mathrm{L}$ $\mathrm{Cd}, 65.47 \%$ of $\mathrm{Cd}$ was extracted in the form of $\mathrm{NaCl}$, followed by ethanol, accounting for $29.38 \%$. The proportion of water extraction is relatively small, only $3.66 \%$. $\mathrm{Cd}$ in roots mainly exists in the form of $\mathrm{NaCl}$ extraction states.

The speciation of $\mathrm{Cd}$ in stem was different from that

$\begin{array}{llll}44.19 \pm 1.85 & 3.72 \pm 0.16 & 0.02 \pm 0.00 & 104.67 \pm 5.23 \\ 65.47 \pm 2.41 & 1.44 \pm 0.04 & 0.05 \pm 0.00 & 122.72 \pm 4.91 \\ 66.76 \pm 4.24 & 6.24 \pm 0.45 & 0.09 \pm 0.00 & 127.02 \pm 2.54 \\ 68.19 \pm 3.29 & 7.06 \pm 0.27 & 0.10 \pm 0.00 & 96.49 \pm 3.68\end{array}$

in roots. As shown in Fig.2, under $20 \mathrm{mg} / \mathrm{L} \mathrm{Cd}$ exposure, $59.75 \%$ of $\mathrm{Cd}$ in the stem was in the form of water extraction, $24.40 \%$ in the form of $\mathrm{NaCl}$ extraction, $9.53 \%$ in the form of ethanol extraction and $6.31 \%$ in the form of acetate extraction. Under the exposure of $100 \mathrm{mg} / \mathrm{L} \mathrm{Cd}$, $66.76 \% \mathrm{Cd}$ was extracted in the form of $\mathrm{NaCl}$ extraction, $17.18 \%$ in the form of water, $9.72 \%$ in the form of ethanol and $6.24 \%$ in the form of acetic acid.

The speciation of $\mathrm{Cd}$ in leaves were not significantly affected by $\mathrm{Cd}$ exposure. The leaves of Sedum alfredii Hance treated with $20 \mathrm{mg} / \mathrm{L} \mathrm{Cd}$ and $100 \mathrm{mg} / \mathrm{L} \mathrm{Cd}$ were mainly $\mathrm{NaCl}$ extraction, followed by ethanol extraction, water extraction and acetic acid extraction. Under the treatment of $20 \mathrm{mg} / \mathrm{L} \mathrm{Cd}$, the extraction state of $\mathrm{NaCl}$ was $44.19 \%$, that of ethanol was $26.70 \%$, that of water was $25.37 \%$ and that of acetate was $3.72 \%$. Under the treatment of $100 \mathrm{mg} / \mathrm{L} \mathrm{Cd}, 68.19 \%$ of the leaves were $\mathrm{NaCl}$ extraction state, $12.93 \%$ were water extraction state, $11.71 \%$ were ethanol extraction state and $7.06 \%$ were acetic acid extraction state.
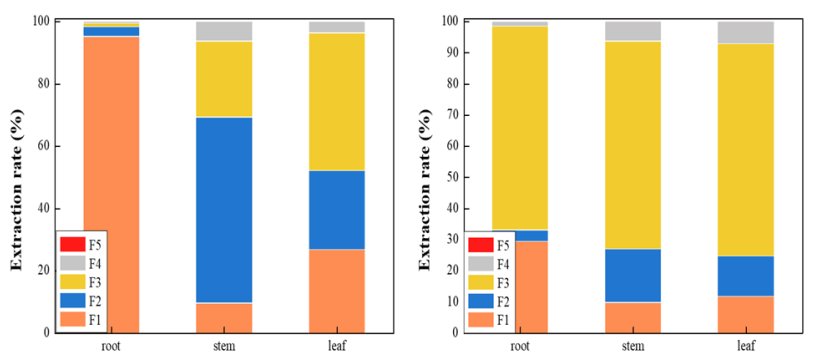

Fig.2 The speciation of cadmium in root of Sedum alfredii Hance under $20 \mathrm{mg} / \mathrm{L}$ (left) and $100 \mathrm{mg} / \mathrm{L}$ (right) Cd exposure

Fraction 1: $80 \%$ ethanol extraction speciation; Fraction 2: Deionized water extraction speciation; Fraction 3: $0.1 \mathrm{~mol} / \mathrm{L}$ $\mathrm{NaCl}$ extraction speciation; Fraction 4: $2 \%$ acetic acid extraction speciation; Fraction 5: residual speciation

It can be seen from Fig. 2 that, under the treatment of $20 \mathrm{mg} / \mathrm{L}$ and $100 \mathrm{mg} / \mathrm{L} \mathrm{Cd}$, the higher the position was, the more $\mathrm{NaCl}$ extraction state content was in all parts from aboveground part to aboveground part. Under the treatment of $100 \mathrm{mg} / \mathrm{L} \mathrm{Cd}$, the extraction state of acetic acid also showed the same rule. This may be the reason for the less toxicity of the $\mathrm{NaCl}$ and acetic acid extracts.

\subsection{The different speciation of $\mathrm{Cd}$ were extracted by two-step extraction method}

Due to the literature review, we could not find the explicit basis for the extraction methods of different speciation of HMs in plants, nor could we find the basis for the selection of extractant sequence in the continuous extraction method. Therefore, the extraction sequence of ethanol and water is changed in this section, that is, the first step is water extraction, the second step is ethanol extraction, and the change of extraction rate of extraction agent is analyzed after the exchange of the order. In this section, a two-step continuous extraction experiment was 
carried out with Sedum alfredii Hance under $20 \mathrm{mg} / \mathrm{L} \mathrm{Cd}$ exposure, and compared with the first step ethanol extraction and the second step water extraction in sections 3.2 and 3.3.

The two-step extraction method was used to extract different speciation of $\mathrm{Cd}$ in the Sedum alfredii Hance. From the point of view of the whole plant, water extracted Cd 80.39 ug, accounting for $13.38 \%$ of the total
Cd. 36.33ug Cd was extracted by ethanol, accounting for $6.05 \%$ of the total $\mathrm{Cd}$ (as shown in Table 3 ). In the experiment in Section 3.2, ethanol extracted $\mathrm{Cd}$ accounted for $31.89 \%$ of the total $\mathrm{Cd}$, and water extracted $\mathrm{Cd}$ accounted for $30.09 \%$ of the total $\mathrm{Cd}$. Therefore, changing the extraction sequence of the extractant will reduce the extraction capacity of the extractant

Table 3 The extraction concent and extraction rate of two - step extraction method

\begin{tabular}{cccccc}
\hline \multirow{2}{*}{$\begin{array}{c}\text { Cd } \\
\text { Treatment }(\mathbf{m g} / \mathbf{L})\end{array}$} & Plant & \multicolumn{2}{c}{ Extraction concent (ug) } & \multicolumn{2}{c}{ Extraction rate (\%) } \\
\cline { 3 - 5 } & organs & Deionized water & $\mathbf{8 0 \%}$ ethanol & Deionized water & $\mathbf{8 0 \% \text { ethanol }}$ \\
\hline \multirow{2}{*}{20} & root & $13.08 \pm 0.52$ & $2.27 \pm 0.13$ & $18.73 \pm 0.56$ & $3.25 \pm 0.16$ \\
& stem & $15.88 \pm 0.79$ & $9.13 \pm 0.37$ & $10.14 \pm 0.31$ & $13.74 \pm 0.69$ \\
& leaf & $51.43 \pm 1.54$ & $24.93 \pm 1.25$ & $6.63 \pm 0.23$ & $13.38 \pm 0.54$ \\
& plant & $80.39 \pm 4.02$ & $36.33 \pm 0.73$ & $6.05 \pm 0.30$ \\
\hline
\end{tabular}

As shown in Fig.3, water and ethanol were used to extract $\mathrm{Cd}$ from the roots, stems and leaves, and the extraction rate of water was both higher than that of ethanol. Water and ethanol accounted for $18.73 \%$ and $3.25 \%$ respectively. $10.14 \%$ and $5.83 \%$ of the stems were extracted by water and ethanol. In the leaves, $13.74 \%$ were extracted by water and $6.66 \%$ by ethanol.

Compared with the four-step extraction method, the first step was ethanol extraction (extraction rate 95.09\%) and the second step was water extraction (3.16\%). When $\mathrm{Cd}$ was extracted from roots, the extraction rate of ethanol was greatly reduced, while the extraction rate of water was increased. For $\mathrm{Cd}$ in stems, ethanol and water accounted for $9.53 \%$ and $59.75 \%$ by four-step extraction method, and the extraction rate of two-step extraction method was both reduced. For $\mathrm{Cd}$ in leaves, the extraction rates of ethanol and water by four-step extraction method were $26.70 \%$ and $25.37 \%$, respectively, higher than that of water $(13.74 \%)$ and ethanol $(6.66 \%)$ by two-step extraction method. In conclusion, although the speciation of $\mathrm{Cd}$ is different in roots, stems and leaves, the extraction sequence of the exchange extractant is not conducive to the extraction of $\mathrm{Cd}$ speciation.

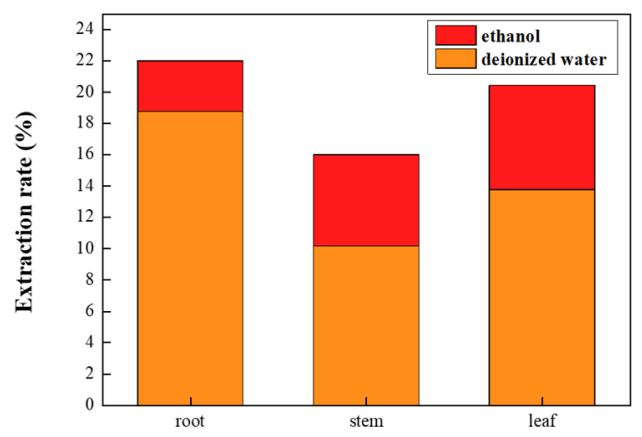

Fig.3 The extraction rate of two-step continuous extraction method

\section{Discussion}

(1) Almost all Cd can be extracted from the Sedum alfredii Hance by four successive extraction steps of ethanol, water, $\mathrm{NaCl}$ and acetic acid. $\mathrm{Xu}$ et al. extracted
Cd in Siegesbeckia orientalis L. by a five-step continuous extraction method (ethanol, water, $\mathrm{NaCl}$, acetic acid and hydrochloric acid), and the extraction rate of the first four extracts reached more than $90 \%{ }^{[6]}$. However, Yang et al. ${ }^{[7]}$ used this method to extract different speciation of lead in rice, and found that the extraction form of hydrochloric acid accounted for $28 \%-52 \%$, followed by acetic acid, $\mathrm{NaCl}$, water and ethanol, which was very low, contrary to the conclusion of this study. This may be the result of the self-regulation mechanism of hyperaccumulator to reduce HMs toxicity.

(2) The toxicity of $\mathrm{Cd}$ is directly related to its speciation. In general, ethanol and water-extracted states are more cytotoxic to plants because inorganic salts such as nitrate and chloride are thought to have strong migratory capacity. However, the $\mathrm{NaCl}$ and acetic acid extraction showed weak mobility and cytotoxicity. In this paper, the hyperaccumulator Sedum alfredii Hance was used as the material, and the exogenous $\mathrm{Cd}$ exposure was added to extract $\mathrm{Cd}$ from the plants continuously with four extractant. It was found that the extracted state of $\mathrm{NaCl}$ accounted for $34.11 \%$ of the plants under $20 \mathrm{mg} / \mathrm{L}$ $\mathrm{Cd}$ exposure, and $67.33 \%$ of the plants under $100 \mathrm{mg} / \mathrm{L}$ $\mathrm{Cd}$ exposure. The high proportion of $\mathrm{NaCl}$ extraction is due to the fact that metallothionins in the cells of hyperaccumulator can chelate with HMs and form complex with low toxicity after being stressed by $\mathrm{Cd}$. Wei et al. ${ }^{[8]}$ used the five-step continuous extraction method to extract $\mathrm{Cd}$ from the hyperaccumulator Solanum nigrum L., and found the same rule.

(3) From the underground part to the aboveground part (root $\rightarrow$ stem $\rightarrow$ leaf), the $\mathrm{NaCl}$ extraction state increased successively, that is, Sedum alfredii Hance transported the less toxic $\mathrm{NaCl}$ extraction state upward. We hypothesized that Sedum alfredii Hance had selective migration for different speciation of $\mathrm{Cd}$, especially for the less toxic $\mathrm{NaCl}$ and acetic acid extraction states. Further study is needed on the migration ability of different speciation.

(4) The extraction rate of two-step extraction method (the first step is water extraction, the second step is ethanol extraction) is lower than that of ethanol extraction and then water extraction. Literature review 
found that the extraction rate of water is generally not more than $30 \%$. Xu et al. ${ }^{[9]}$ extracted different speciation of arsenic in lentinus edodes with water, and the extraction rate was about $25 \%$. Gilon ${ }^{[10]}$ used water at $60^{\circ} \mathrm{C}$ to extract selenium from selenium-rich yeast, and the extraction rate was $20 \%$. In this study, Cd was extracted with normal temperature water, and the extraction rate was only $13.38 \%$. Therefore, the order of exchange of extractant reduces its extraction capacity. The extraction yield of ethanol was only $6.05 \%$, which was far lower than that of ethanol as the first order. To sum up, the extraction effect of HMs in plants is better when ethanol is placed in the first extraction sequence and water in the second extraction sequence.

\section{Conclusion}

(1) The four-step continuous extraction method (80\% ethanol, deionized water, $0.1 \mathrm{~mol} / \mathrm{L} \mathrm{NaCl}, 2 \%$ acetic acid) can extract more than $90 \% \mathrm{Cd}$ from the Sedum alfredii Hance. The recoveries ranged from $86.12 \%$ to $127.02 \%$, which met the requirements of speciation analysis.

(2) $\mathrm{Cd}$ is mainly extracted from $\mathrm{NaCl}$ in the Sedum alfredii Hance. The $\mathrm{Cd}$ extracted in the $\mathrm{NaCl}$ extraction state binds to pectate and protein, and has low toxicity and little damage to cells, which is one of the important mechanisms of Sedum alfredii Hance against Cd toxicity.

(3) Sedum sedum can transfer the low toxicity form to the aboveground. From the underground part to the aboveground part of the plant, the $\mathrm{NaCl}$ extraction states in various organs (roots, stems and leaves) gradually increased, and the migration of different speciation of $\mathrm{Cd}$ needs to be further studied.

(4) Changing the extraction sequence of ethanol and water is not conducive to the extraction of HMs in plants. The extraction rate of ethanol decreased from $31.89 \%$ to $6.06 \%$, and the extraction rate of water decreased from $30.09 \%$ to $13.38 \%$.

\section{Acknowledgments}

This work was supported by the Zhaoqing Science and Technology Project (2018N006), The Technology Innovation Project of Zhaoqing (201904030103) and the Guangdong College Students' Innovative Project (X201910580158).

\section{References}

1. Wang, W., M. Meng, and L. Li, 2019, Arsenic detoxification in Eucalyptus: subcellular distribution, chemical forms, and sulfhydryl substances. Environ Sci Pollut Res Int. 26(24): p. 24372-24379.

2. Zhang, W., K. Lin, J. Zhou, W. Zhang, L. Liu, and Q. Zhang, 2014, Cadmium accumulation, sub-cellular distribution and chemical forms in rice seedling in the presence of sulfur. Environ Toxicol Pharmacol. 37(1): p. 348-53.

3. Wang, X. and D. Liu, 2017, Integration of cerium chemical forms and subcellular distribution to understand cerium tolerance mechanism in the rice seedlings. Environ Sci Pollut Res Int. 24(19): p. 16336-16343.

4. Lai, H.Y., 2015, Subcellular distribution and chemical forms of cadmium in Impatiens walleriana in relation to its phytoextraction potential. Chemosphere. 138(nov.): p. 370-376.

5. Li, X., B.J. Coles, M.H. Ramsey, and I. Thornton, 1995, Sequential extraction of soils for multielement analysis by ICP-AES. Chemical Geology. 124(1-2): p. 109-123.

6. $\mathrm{Xu}, \mathrm{X} ., 2018$. Mechanisms of uptake and tolerance of hyperaccumulator plant Siegesbeckia orientalis L. to cadmium stress. Sichuan Agricultural University.

7. Yang, J., Zha, Yan., Liu, Hong., 1999, The distribution and chemical forms of $\mathrm{Cd}, \mathrm{Cu}, \mathrm{Pb}$ in polluted seeds. China Environmental Science. 19(6): p. 500-504.

8. Wei, S., X. Zeng, S. Wang, J. Zhu, D. Ji, Y. Li, and H. Jiao, 2014, Hyperaccumulative property of Solanum nigrum $\mathrm{L}$. to $\mathrm{Cd}$ explored from cell membrane permeability, subcellular distribution, and chemical form. Journal of Soils and Sediments. 14(3): p. 558-566.

9. $\mathrm{Xu}, \mathrm{J} ., 2016$, Arsenic Speciation Analysis of Lentinus edodes by Ultrasonic-Assisted Extraction-High Performance Liquid Chromatography-Inductively Coupled Plasma Mass Spectrometry. Food science. 37: p. 216-221.

10. N. Gilon, A.A., M. Astruc and M. Potin-Gautier, 1995, Selenoamino Acid Speciation Using HPLC-ETAAS following an enzymic hydrolysis of selenoprotein. Applied Organometallic Chemistry. 9(7): p. 623-628. 